\title{
Prevalence and Prognostic Implications of Pre-Diabetic State in Patients With Heart Failure
}

\author{
Yuya Matsue, MD; Makoto Suzuki, MD, PhD; Rena Nakamura, MD; Masami Abe, MD; Maki Ono, MD; \\ Seigo Yoshida, MD; Mie Seya, MD; Ryota Iwatsuka, MD; Akira Mizukami, MD; \\ Masahiko Setoguchi, MD; Wataru Nagahori, MD; Masakazu Ohno, MD; \\ Akihiko Matsumura, MD; Yuji Hashimoto, MD, PhD
}

\begin{abstract}
Background: Diabetes mellitus (DM) is a risk factor of poor prognosis in patients with heart failure (HF). The prevalence and prognostic impact of the pre-diabetic state, however, are not well understood.

Methods and Results: One hundred and thirty-six consecutive patients admitted due to HF were included in this prospective study. The 75-g oral glucose tolerance test (OGTT) was performed in all patients without known DM, and patients were classified into normal glucose tolerance (NGT), impaired fasting glucose (IFG), impaired glucose tolerance (IGT), and DM groups. Forty-two of the 136 patients had previously been diagnosed with diabetes. Of the remaining 94 patients without known diabetes, 35 (37.2\%) patients were classified as NGT, 9 (9.6\%) as having IFG, $37(39.4 \%)$ were classified as having IGT, and $13(13.8 \%)$ were newly diagnosed with DM. During follow-up, patients with DM or IGT had significantly lower major adverse cardiac and cerebrovascular event (MACCE)-free rates than NGT patients $(P=0.006, P=0.036$, respectively). IFG, however, was not significantly related to increased MACCE risk. The presence of IGT (hazard ratio [HR], 4.51; $\mathrm{P}=0.011$ ) and $\mathrm{DM}(\mathrm{HR}, 4.74 ; \mathrm{P}=0.005)$ were independent predictors of MACCE even after multivariate analysis.
\end{abstract}

Conclusions: IGT and DM contribute to adverse prognosis in patients with HF. It is feasible to perform diabetes screening using OGTT in patients with HF for risk stratification. (Circ $J$ 2011; 75: 2833-2839)

Key Words: Diabetes; Heart failure; Impaired glucose tolerance

D iabetes mellitus (DM) is an important risk factor for heart failure (HF) independent from coronary heart disease. ${ }^{1}$ Recently, epidemiological studies including the Framingham Heart Study have shown that the presence of DM increases the risk of HF by approximately twofold in men and fivefold in women. ${ }^{2}$ Conversely, among patients with a primary hospital discharge diagnosis of $\mathrm{HF}, 38 \%$ had concomitant DM, ${ }^{3}$ and the presence of DM has also been shown to be an independent predictor of poor outcome. ${ }^{4,5}$ The prevalence of glucose intolerance was reported to be approximately $50 \%$ in Japanese patients with symptomatic HF. ${ }^{6}$ Impaired glucose tolerance (IGT), which is considered as an early stage of DM, has also been shown to be a common comorbidity and an independent risk factor for adverse outcome in patients with $\mathrm{HF} .^{7-10}$ Precise evaluation of glucose tolerance is required for risk stratification, even in patients with HF. Most studies performed to date, however, have not included diagnosis of glucose intolerance using the oral glucose tolerance test (OGTT).

The present study was performed to clarify the relationship between glucose metabolism and prognosis in Japanese patients with chronic HF.

Methods
Subjects
We performed a prospective and observational study of all
patients admitted to Kameda Medical Center with a diagno-
sis of congestive HF between January 2009 and April 2011.
The attending physician diagnosed HF according to the Fram-
ingham criteria. ${ }^{11}$ Patients with acute myocardial infarction,
valvular disease, end-stage chronic kidney disease (estimated
glomerular filtration rate $<15 \mathrm{ml} \cdot \mathrm{kg}^{-1} \cdot 1.73^{-2}$ ), type 1 diabetes,
infection, and malignant disease were excluded. Patients were
diagnosed as having HF with preserved ejection fraction
(HFPEF) if ejection fraction was $\geq 50 \%$, and HF with reduced
ejection fraction (HFREF) if ejection fraction was $<50 \%$.
According to Japan Diabetes Society guidelines, all patients
with newly diagnosed diabetes, IGT, and impaired fasting
glucose (IFG) were first treated with therapeutic lifestyle
change. All patients gave their written informed consent, and

\section{Subjects}

patients admitted to Kameda Medical Center with a diagnosis of congestive HF between January 2009 and April 2011. The attending physician diagnosed HF according to the Framingham criteria. ${ }^{11}$ Patients with acute myocardial infarction, valvular disease, end-stage chronic kidney disease (estimated glomerular filtration rate $<15 \mathrm{ml} \cdot \mathrm{kg}^{-1} \cdot 1.73^{-2}$, type 1 diabetes, diagnosed as having $\mathrm{HF}$ with preserved ejection fraction (HFPEF) if ejection fraction was $\geq 50 \%$, and HF with reduced ejection fraction (HFREF) if ejection fraction was $<50 \%$. with newly diagnosed diabetes, IGT, and impaired fasting change. All patients gave their written informed consent, and

Received July 19, 2011; revised manuscript received August 13, 2011; accepted September 2, 2011; released online October 19, 2011 Time for primary review: 16 days

Division of Cardiology, Department of Medicine, Kameda Medical Center, Chiba, Japan

Mailing address: Yuya Matsue, MD, Division of Cardiology, Department of Medicine, Kameda Medical Center, 929 Higashi-chou, Kamogawa, Chiba 296-8602, Japan. E-mail: yuyam@kameda.jp

ISSN-1346-9843 doi:10.1253/circj.CJ-11-0754

All rights are reserved to the Japanese Circulation Society. For permissions, please e-mail: cj@j-circ.or.jp 
Table 1. Baseline Subject Characteristics vs. Glucometabolic Classification

\begin{tabular}{|c|c|c|c|c|c|}
\hline Characteristics & $\begin{array}{c}\text { NGT } \\
(n=35)\end{array}$ & $\begin{array}{c}\text { IFG } \\
(n=9)\end{array}$ & $\begin{array}{c}\text { IGT } \\
(n=37)\end{array}$ & $\underset{(n=55)}{D M}$ & $P$ value \\
\hline Age (years) & $62.4 \pm 11.3$ & $71.0 \pm 11.8$ & $67.2 \pm 11.6$ & $74.8 \pm 10.2$ & 0.512 \\
\hline Male & $18(51.4)$ & $2(22.2)$ & $20(54.1)$ & $22(40.0)$ & 0.238 \\
\hline Smoking & $13(37.2)$ & $5(55.6)$ & $16(43.2)$ & $31(58.2)$ & 0.443 \\
\hline $\mathrm{HF}$ ischemic etiology & $9(25.7)$ & $2(22.2)$ & $8(21.6)$ & $17(30.9)$ & 0.778 \\
\hline NYHA class & $1.49 \pm 0.51$ & $1.44 \pm 0.53$ & $1.38 \pm 0.59$ & $1.47 \pm 0.66$ & 0.865 \\
\hline BMI & $24.4 \pm 2.8$ & $24.9 \pm 2.8$ & $24.6 \pm 3.5$ & $24.7 \pm 3.8$ & 0.967 \\
\hline $\mathrm{SBP}(\mathrm{mmHg})$ & $121.3 \pm 14.2$ & $124.4 \pm 9.0$ & $119.9 \pm 13.5$ & $124.8 \pm 14.5$ & 0.343 \\
\hline $\mathrm{DBP}(\mathrm{mmHg})$ & $69.0 \pm 10.2$ & $71.7 \pm 12.3$ & $72.7 \pm 12.5$ & $73.1 \pm 11.1$ & 0.313 \\
\hline Heart rate (beats/min) & $59.9 \pm 8.8$ & $59.9 \pm 8.6$ & $57.8 \pm 9.7$ & $58.8 \pm 8.5$ & 0.769 \\
\hline $\operatorname{LVEF}(\%)$ & $49.5 \pm 12.8$ & $50.7 \pm 12.0$ & $48.8 \pm 12.5$ & $53.5 \pm 14.1$ & 0.328 \\
\hline End-diastolic diameter (mm) & $55.0 \pm 8.8$ & $56.6 \pm 8.6$ & $55.7 \pm 6.8$ & $54.2 \pm 7.3$ & 0.754 \\
\hline End-systolic diameter (mm) & $41.2 \pm 9.6$ & $42.3 \pm 8.9$ & $41.9 \pm 9.6$ & $40.0 \pm 9.7$ & 0.79 \\
\hline $\mathrm{LAD}(\mathrm{mm})$ & $45.7 \pm 6.7$ & $46.4 \pm 10.6$ & $45.8 \pm 7.2$ & $45.4 \pm 8.1$ & 0.979 \\
\hline HFPEF & $14(40.0)$ & $4(44.4)$ & $20(54.1)$ & $34(61.8)$ & 0.224 \\
\hline \multicolumn{6}{|l|}{ Medical history } \\
\hline Hypertension & $20(57.1)$ & $7(77.8)$ & $19(51.4)$ & $38(69.1)$ & 0.236 \\
\hline Dyslipidemia & $11(31.4)$ & $2(22.2)$ & $9(24.3)$ & $22(40.0)$ & 0.392 \\
\hline Cerebral infarction & $5(5.5)$ & $3(12.0)$ & $8(8.2)$ & $5(10.4)$ & 0.637 \\
\hline Atrial fibrillation & $19(54.3)$ & $5(55.6)$ & $22(59.5)$ & $24(43.6)$ & 0.481 \\
\hline \multicolumn{6}{|l|}{ Medications } \\
\hline Aspirin & $13(37.1)$ & $5(55.6)$ & $10(27.0)$ & $22(40.0)$ & 0.373 \\
\hline ACEI & $9(25.7)$ & $2(22.2)$ & $11(29.7)$ & 17 (30.9) & 0.922 \\
\hline ARB & $10(28.6)$ & $3(33.3)$ & $14(37.8)$ & $23(41.8)$ & 0.642 \\
\hline$\beta$-blocker & $22(62.9)$ & $4(44.4)$ & $21(56.8)$ & $35(63.6)$ & 0.684 \\
\hline Statin & $15(42.9)$ & $4(44.4)$ & $15(40.5)$ & $29(52.7)$ & 0.662 \\
\hline ССВ & $16(45.7)$ & $4(44.4)$ & $15(40.5)$ & $19(34.5)$ & 0.745 \\
\hline Diuretics & $32(91.4)$ & $7(77.8)$ & $31(83.8)$ & $48(87.3)$ & 0.661 \\
\hline Spironolactone & $23(65.7)$ & $5(55.6)$ & $23(62.2)$ & $37(67.3)$ & 0.894 \\
\hline \multicolumn{6}{|l|}{ Therapy for diabetes } \\
\hline Therapeutic lifestyle change & $0(0)$ & $9(100)$ & $37(100)$ & $55(100)$ & $<0.001$ \\
\hline Anti-oral diabetes drug & $0(0)$ & $0(0)$ & $0(0)$ & $18(32.7)$ & $<0.001$ \\
\hline Insulin & $0(0)$ & $0(0)$ & $0(0)$ & $11(20.0)$ & $<0.001$ \\
\hline eGFR $\left(\mathrm{ml} \cdot \mathrm{min}^{-1} \cdot 1.73 \mathrm{~m}^{-2}\right)$ & $49.0 \pm 23.6$ & $41.7 \pm 23.0$ & $50.2 \pm 31.6$ & $46.2 \pm 24.3$ & 0.682 \\
\hline Hemoglobin (g/dl) & $12.1 \pm 1.67$ & $12.3 \pm 1.91$ & $12.3 \pm 1.67$ & $12.5 \pm 1.63$ & 0.713 \\
\hline $\mathrm{HbA}_{1 \mathrm{c}}(\%)$ & $5.26 \pm 0.27$ & $5.68 \pm 0.26$ & $5.90 \pm 0.3$ & $6.28 \pm 0.41$ & $<0.001$ \\
\hline BNP (pg/dl) & $280.1 \pm 279.9$ & $293.1 \pm 237.6$ & $291.5 \pm 375.5$ & $312.9 \pm 330.0$ & 0.971 \\
\hline
\end{tabular}

Data given as mean $\pm \mathrm{SD}$ or $\mathrm{n}(\%)$.

NGT, normal glucose tolerance; IFG, impaired fasting glucose; IGT, impaired glucose tolerance; DM, diabetes mellitus; HF, heart failure; NYHA, New York Heart Association; BMI, body mass index; SBP, systolic blood pressure; $\mathrm{DBP}$, diastolic blood pressure; LVEF, left ventricular ejection fraction; LAD, left atrium diameter; HFPEF, heart failure with preserved ejection fraction; ACEI, angiotensin-converting enzyme inhibitor; ARB, angiotensin receptor blocker; $\mathrm{CCB}$, calcium channel blocker; eGFR, estimated glomerular filtration rate; $\mathrm{Hb}_{1 \mathrm{c}}$, hemoglobin $\mathrm{A}_{1 \mathrm{c}}$; $\mathrm{BNP}$, brain natriuretic peptide.

\begin{tabular}{|lccccc|}
\hline \multicolumn{1}{l}{ Table 2. Adverse Events vs. Glucometabolic Classification } & & & \\
\multicolumn{1}{c}{ Characteristics } & $\begin{array}{c}\text { NGT } \\
\mathbf{( n = 3 5 )}\end{array}$ & $\begin{array}{c}\text { IFG } \\
(\mathbf{n = 9})\end{array}$ & $\begin{array}{c}\text { IGT } \\
(\mathbf{n}=\mathbf{3 7})\end{array}$ & $\begin{array}{c}\text { DM } \\
(\mathbf{n}=\mathbf{5 5})\end{array}$ & P value \\
Rehospitalization for HF & $2(5.9)$ & $0(0)$ & $9(23.7)$ & $15(27.3)$ & 0.031 \\
Cardiovascular death & $1(2.9)$ & $1(11.1)$ & $2(5.3)$ & $4(7.3)$ & 0.754 \\
Cerebral infarction & $1(2.9)$ & $0(0)$ & $1(2.6)$ & $1(1.8)$ & 0.949 \\
MACCE & $4(11.8)$ & $1(11.1)$ & $12(31.6)$ & $20(36.4)$ & 0.047 \\
Cardiovascular events & $3(8.8)$ & $1(11.1)$ & $11(28.9)$ & $19(34.5)$ & 0.034 \\
\hline
\end{tabular}

Data given as $\mathrm{n}(\%)$.

MACCE, major adverse cardiac and cerebrovascular events. Other abbreviations see in Table 1. 


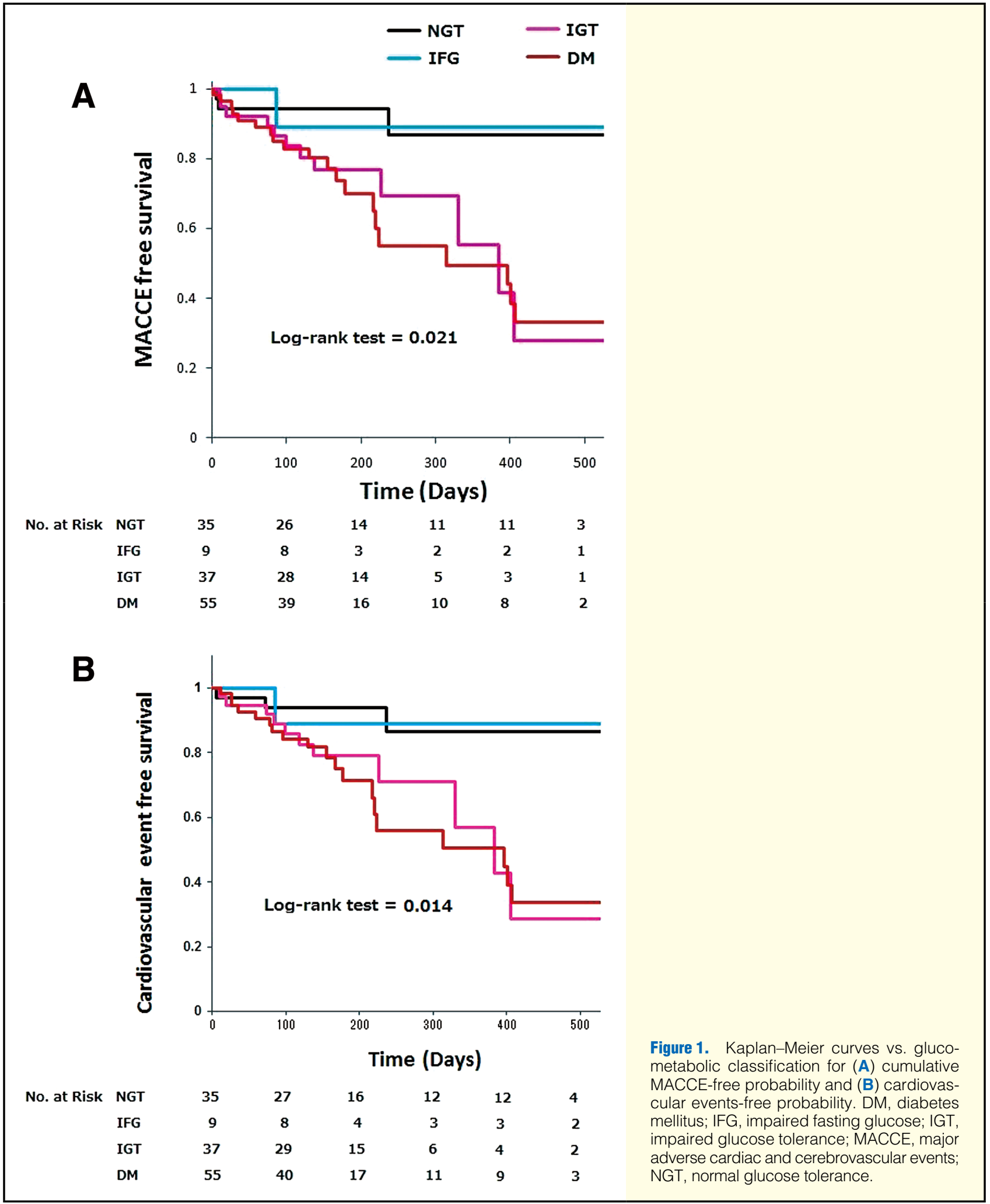

the study was approved by the local ethics committee.

\section{Classification of Abnormal Glucose Tolerance}

All patients included in this study who did not have a previous history of DM underwent 75-g OGTT on the day of discharge via the standard method after overnight fasting. Sub- jects with abnormal glucose tolerance were classified into 4 groups, that is, normal glucose tolerance (NGT), IFG, IGT, and DM, according to the Criteria for Glucometabolic Disturbance established by the World Health Organization. ${ }^{12}$ Previously known DM was defined as clinical history of oral hypoglycemic agent and/or insulin use and fasting plasma glucose 


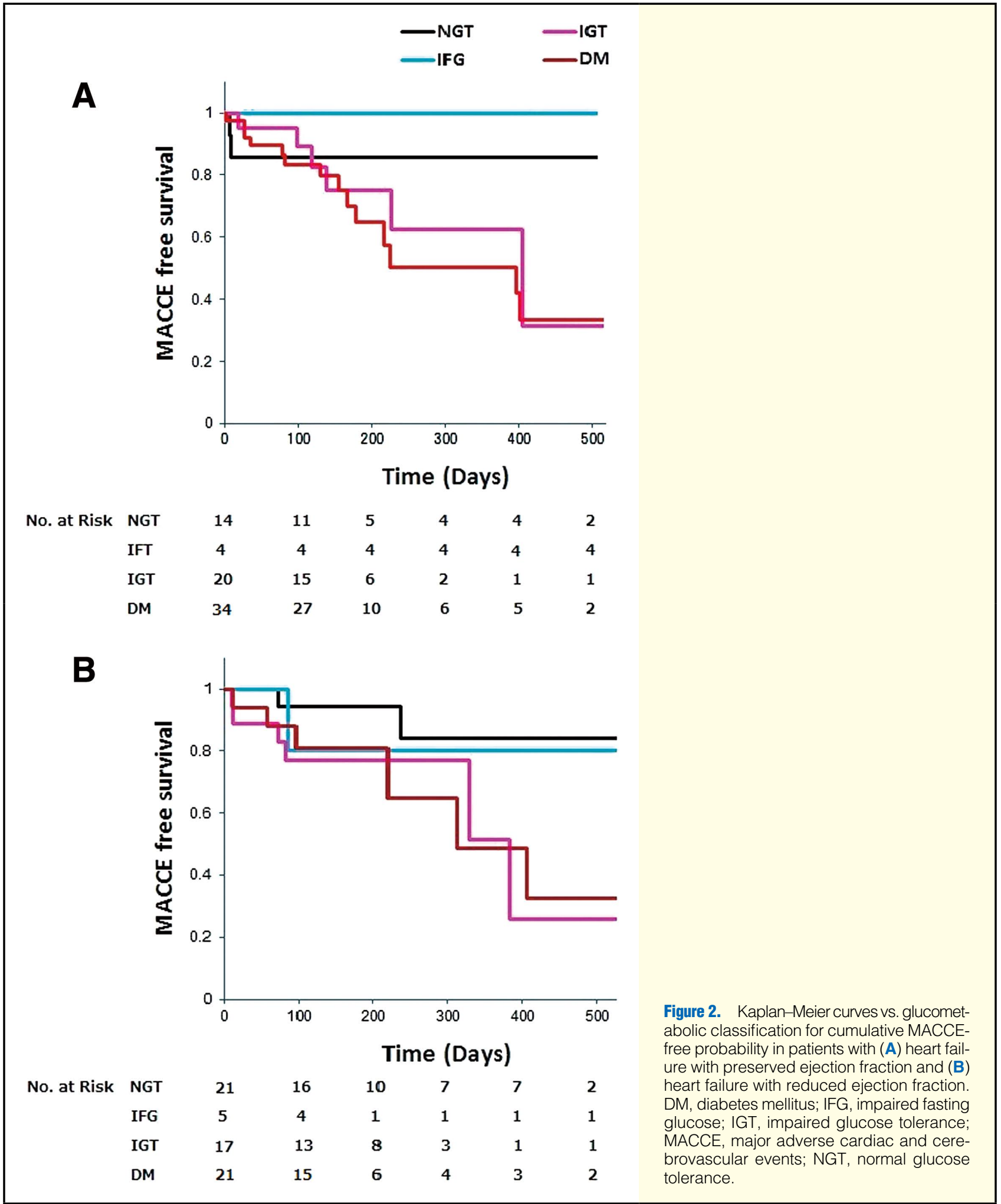

levels $>126 \mathrm{mg} / \mathrm{dl}$. The other patients were urged to have their glucose tolerance evaluated on 75-g OGTT. NGT was defined as fasting glucose level $<126 \mathrm{mg} / \mathrm{dl}$ and a 2 -h glucose level $\geq 200 \mathrm{mg} / \mathrm{dl}$. NGT was defined as fasting glucose level $<110 \mathrm{mg} / \mathrm{dl}$ and 2 -h glucose level $<140 \mathrm{mg} / \mathrm{dl}$. In the remaining patients, IGT was defined as fasting glucose level $<126 \mathrm{mg} / \mathrm{dl}$ and 2 -h glucose level $\geq 140 \mathrm{mg} / \mathrm{dl}$ or fasting glu- cose level 110-125 mg/dl and 2-h glucose level $<140 \mathrm{mg} / \mathrm{dl}$.

\section{Data Measurement}

Patients with systolic blood pressure $>140 \mathrm{mmHg}$ and/or diastolic pressure $>90 \mathrm{mmHg}$ and those taking anti-hypertensive agents were considered to have hypertension. Hypercholesterolemia was defined as serum total cholesterol level 


\begin{tabular}{|c|c|c|c|c|}
\hline & \multicolumn{2}{|c|}{ Univariate } & \multicolumn{2}{|c|}{ Multivariate } \\
\hline & HR (95\%Cl) & $P$ value & HR $(95 \% \mathrm{Cl})$ & $P$ value \\
\hline Age (years) & $1.06(1.01-1.11)$ & 0.007 & $1.04(0.99-1.08)$ & 0.099 \\
\hline Male & $1.02(0.48-2.18)$ & 0.959 & & \\
\hline Smoking & $0.82(0.39-1.68)$ & 0.585 & & \\
\hline $\mathrm{HF}$ ischemic etiology & $1.25(0.54-2.89)$ & 0.599 & & \\
\hline NYHA class & $0.82(0.42-1.59)$ & 0.561 & & \\
\hline $\mathrm{BMI}$ & $0.93(0.83-1.05)$ & 0.237 & & \\
\hline $\mathrm{SBP}(\mathrm{mmHg})$ & $1.03(1.01-1.06)$ & 0.044 & $1.02(0.99-1.04)$ & 0.173 \\
\hline $\mathrm{DBP}(\mathrm{mmHg})$ & $1.01(0.97-1.04)$ & 0.827 & & \\
\hline Heart rate (beats/min) & $0.99(0.95-1.03)$ & 0.642 & & \\
\hline $\operatorname{LVEF}(\%)$ & $0.99(0.97-1.03)$ & 0.858 & & \\
\hline End-diastolic diameter (mm) & $1.02(0.97-1.07)$ & 0.568 & & \\
\hline End-systolic diameter (mm) & $1.01(0.97-1.05)$ & 0.589 & & \\
\hline LAD $(\mathrm{mm})$ & $0.95(0.91-1.01)$ & 0.113 & & \\
\hline HFPEF & $1.291(0.67-2.49)$ & 0.446 & & \\
\hline \multicolumn{5}{|l|}{ Medical history } \\
\hline Hypertension & $1.20(0.55-2.63)$ & 0.649 & & \\
\hline Dyslipidemia & $1.12(0.87-1.92)$ & 0.689 & & \\
\hline Atrial fibrillation & $0.55(0.25-1.17)$ & 0.121 & & \\
\hline \multicolumn{5}{|l|}{ Medications } \\
\hline Aspirin & $1.70(0.79-3.67)$ & 0.177 & & \\
\hline ACEI & $0.61(0.25-1.47)$ & 0.269 & & \\
\hline ARB & $1.06(0.49-2.33)$ & 0.874 & & \\
\hline$\beta$-blocker & $0.82(0.38-1.76)$ & 0.607 & & \\
\hline Statin & $0.98(0.46-2.09)$ & 0.957 & & \\
\hline $\mathrm{CCB}$ & $1.05(0.49-2.27)$ & 0.903 & & \\
\hline Diuretics & $0.54(0.19-1.51)$ & 0.237 & & \\
\hline Spironolactone & $1.19(0.53-2.65)$ & 0.67 & & \\
\hline eGFR $\left(\mathrm{ml} \cdot \mathrm{min}^{-1} \cdot 1.73 \mathrm{~m}^{-2}\right)$ & $1.01(0.99-1.02)$ & 0.678 & & \\
\hline Hemoglobin (g/dl) & $0.97(0.94-1.60)$ & 0.054 & $1.13(0.92-1.38)$ & 0.256 \\
\hline $\mathrm{HbA}_{1 \mathrm{c}}(\%)$ & $1.67(0.83-3.50)$ & 0.151 & & \\
\hline BNP (pg/dl) & $1.002(1.001-1.004)$ & 0.002 & $1.001(1.000-1.002)$ & 0.023 \\
\hline \multicolumn{5}{|l|}{ Glucose intolerance } \\
\hline NGT & 1.0 & & 1.0 & \\
\hline IFG & $0.94(0.09-9.60)$ & 0.957 & $1.08(0.12-9.68)$ & 0.948 \\
\hline IGT & $3.46(0.99-12.05)$ & 0.051 & $4.51(1.41-14.47)$ & 0.011 \\
\hline DM & $4.29(1.32-13.94)$ & 0.016 & $4.74(1.58-14.23)$ & 0.005 \\
\hline
\end{tabular}

Variables with $\mathrm{P}<0.1$ on univariate analysis were included in the multivariate model. $\mathrm{HR}$, hazard ratio; $\mathrm{Cl}$, confidence interval. Other abbreviations see in Tables 1,2.

$\geq 220 \mathrm{mg} / \mathrm{dl}$ or the requirement of treatment with lipid-lowering agents. Patients were considered smokers if they were current smokers.

A baseline blood sample was collected on the day of discharge. Estimated glomerular filtration rate was calculated using the Modification of Diet and Renal Disease equation coefficients modified for Japanese patients. ${ }^{13}$ Left ventricular ejection fraction was measured at the time of discharge on 2-D echocardiography using the modified Simpson method. Medication data were collected at the end of follow-up.

\section{Follow-up}

All patients were followed up at the outpatient clinic and data regarding major adverse cardiac and cerebrovascular events (MACCE) were collected. Patient outcomes were assessed based on MACCE, which included death from cardiac causes, non-fatal myocardial infarction, unstable angina, rehospitalization because of congestive HF, and cerebral infarction. Apart from MACCE, only cardiovascular death and rehospitalization because of congestive HF were classified as cardiovascular events. Cerebral infarction was diagnosed by the presence of a neurological deficit confirmed on computed tomography or magnetic resonance imaging.

\section{Statistical Analysis}

Baseline characteristics were analyzed for significance of differences between groups using 1-way analysis of variance (ANOVA) for continuous variables and the chi-squared or Fisher's exact test for categorical variables. Event-free survival curves were constructed using the Kaplan-Meier survival method and were compared using log-rank statistics. Survival period was defined as the interval between the day of discharge and the time of MACCE.

We calculated hazard ratios (HRs) derived from the Cox proportional hazard model to evaluate the prognostic effects of the presence of IFG, IGT, and DM for the study period. All base- 
line variables, including echocardiographic parameters, were included in regression analysis. Multivariate analysis was performed using all variables with $\mathrm{P}<0.1$ on univariate analysis.

Results are given as mean $\pm \mathrm{SD}, \mathrm{n}(\%)$, or HR with $95 \%$ confidence interval $(95 \% \mathrm{CI})$. All statistical tests were 2-sided, and $\mathrm{P}<0.05$ was considered significant in all analyses. Data analysis was performed using SPSS 19.0 (SPSS, Chicago, IL, USA).

\section{Results}

\section{Baseline Subject Characteristics}

Of the 152 patients admitted during the study period, 5 died due to deterioration of $\mathrm{HF}, 4$ patients required hemodialysis, and 7 patients had hemodynamically significant valvular disease. Therefore, 136 patients were included in the present study. None of the participants dropped out, and all patients were completely followed up at the outpatient clinic. The clinical characteristics of the present patients are listed in Table 1. Forty-two patients were previously diagnosis as having diabetes. Of the 94 patients without known diabetes, 35 (37.2\%) were classified as NGT, $9(9.6 \%)$ were classified as IFG, 37 $(39.4 \%)$ were IGT, and $13(13.8 \%)$ were newly diagnosed as having DM according to 75-g OGTT.

There were no significant differences between the 4 groups except in hemoglobin $\mathrm{A}_{1 \mathrm{c}}\left(\mathrm{HbA}_{1 \mathrm{c}}\right)$, which was higher in DM and IGT patients compared to NGT patients.

\section{MACCE}

Median follow-up was 150 days. The number of MACCE and cardiovascular events are given in Table 2.

The Kaplan-Meier curves in Figure 1A illustrate time to MACCE according to glucose intolerance classification during follow-up, and Figure 1B illustrates time to cardiovascular events. Compared to NGT, the IGT group and DM group had higher risks for MACCE (log-rank $=0.018$ and 0.006 , respectively). There were no significant differences in MACCE-free survival rate between the NGT group and IFG group (logrank=0.926) or between the IGT group and DM group (logrank=0.806). Concerning cardiovascular events, the IGT group and DM group also had higher risk compared to the NGT group (log-rank=0.010 and 0.003 , respectively). We also analyzed the data with regard to HFPEF and HFREF, and this tendency was not changed (Figure 2).

On univariate analysis, age, hemoglobin, B-type natriuretic peptide (BNP), and glucose intolerance classification were associated with higher risk of MACCE. After adjusted multivariate Cox regression analysis, including all variables with $\mathrm{P}<0.1$ on univariate analysis, the presence of IGT (HR, 4.51; 95\%CI: 1.41-14.47; $\mathrm{P}=0.0011)$ and DM (HR, 4.74; 95\%CI: 1.58-14.23; $\mathrm{P}=0.005)$ were significantly associated with increased MACCE risk compared with the NGT group (Table 3). IFG, however, was not significantly related to increased MACCE risk. Age and BNP were also statistically significant on multivariate regression analysis.

\section{Discussion}

The most important findings of the present study were that the prevalence of IGT is high in patients with HF and that IGT, but not IFG, contributes equally to poor prognosis compared to DM even after adjustment for several risk factors.

The prevalence of glucose intolerance in patients with $\mathrm{HF}$ was reported to range from $23 \%$ to $43 \%,,^{7,14-16}$ which is lower than that found in the present study. This wide range reflects the diverse criteria and methods used to identify patients with glucose intolerance. Many studies investigating the prevalence of dysglycemia in HF used fasting or casual glucose levels or only $\mathrm{HbA}_{1 \mathrm{c}}$. Fasting plasma glucose and $\mathrm{HbA}_{1 \mathrm{c}}$ have limited sensitivity for diagnosis of glucose intolerance, in particular IGT. For example, Egstrup et al reported that omitting OGTT would have misclassified $40 \%$ of newly diagnosed cases of diabetes, and by definition all patients with IGT among patients with HFREF. ${ }^{17}$ Some data suggest that $\mathrm{HbA} 1 \mathrm{c}$ measurement in addition to fasting glucose may be of no benefit for detecting IGT or DM in heart disease. In patients with coronary artery disease, $\mathrm{HbA}_{1 \mathrm{c}}$ was less strongly related to the 2-h OGTT glucose level than fasting plasma glucose. In addition, the areas under the receiver operating characteristic curve of fasting glucose and $\mathrm{HbA}_{1 c}$ for detecting IGT or new DM were low (0.76 and 0.71 , respectively) using OGTT as the gold standard. ${ }^{18}$

The prevalence and prognostic impact of IGT and DM have been reported in some studies in which diagnosis was made based only on $\mathrm{HbAlc}_{1 \mathrm{c}}$ and fasting glucose. The CHARM study, which included 2,412 patients with $\mathrm{HF}$, showed that $\mathrm{HbA} 1 \mathrm{c}$ was an independent predictor of cardiovascular death, hospitalization for worsening HF, and total mortality in both diabetic and non-diabetic patients. ${ }^{9}$ In the Reykjavik study, IGT was shown to be an independent predictor of all-cause mortality to a similar degree to that of DM. ${ }^{19}$ In a recent study including only patients with HFREF $(<45 \%)$ and IGT diagnosed previously on 75-g OGTT, HF patients with IGT tended to have a higher mortality rate than those without glucose intolerance. In the present study, IGT and DM contributed similarly to poor prognosis, consistent with these previous results. The diagnosis of IGT in the Reykjavik study, however, was done on 50-g OGTT, not $75 \mathrm{~g}$ as used in the present study. The European Guidelines on diabetes, pre-diabetes, and cardiovascular diseases recommend use of 75 -g OGTT, ${ }^{20}$ and this difference in methodology for diagnosis may have led to underestimation of the prevalence of DM and IGT. In the previous study by Egstrup et al, all patients had HFREF. Patients with HFPEF were included in the present study, and the results indicated a high prevalence and prognostic impact of glucose intolerance.

In the present study, IFG was not a predictor of poor prognosis, which is consistent with previous studies. Two metaanalyses showed that only post-prandial hyperglycemia, but not fasting hyperglycemia, is a good predictor of adverse cardiovascular events. ${ }^{21,22}$ Moreover, even among patients without $\mathrm{HF}$, diastolic function evaluated on echocardiography was shown to be impaired in patients with DM or IGT, but not in those with IFG, compared to NGT. ${ }^{23}$ This may have been why the prognosis of patients with IGT and HF was poorer than that of the other groups. The present study, however, excluded patients with atrial fibrillation; thus, taking into account the high prevalence of atrial fibrillation in $\mathrm{HF}$, these results are not conclusive.

Although several studies have shown that IGT increases cardiovascular morbidity and mortality, it is still unknown as to whether medication for the pre-diabetic state would improve the prognosis. There have been no large-scale, randomized clinical trials addressing this issue, but some data have been reported indicating that intervention for the pre-diabetic state may improve the outcome of this population. Kim et al evaluated the prevalence of IGT in patients with dilated cardiomyopathy, and examined whether an $\alpha$-glucosidase inhibitor could improve the cardiac function and symptoms. Their results showed that the $\alpha$-glucosidase inhibitor improved glucose metabolism and cardiac function. ${ }^{24}$ The STOP-NIDDM study showed that the rate of cardiovascular events was low in 
IGT patients treated with acarbose in comparison with placebo controls. ${ }^{25}$ Because previous studies have shown that postprandial elevated plasma glucose adversely affects endothelial function, inflammatory responses, and increases oxidative stress on the cardiovascular system, ${ }^{26-29}$ preventing progression from the pre-diabetic state to diabetes may be a promising strategy to reduce the morbidity and mortality rates in patients with HF. Further large-scale, prospective clinical trials are necessary to confirm this issue.

To our knowledge, this is the first report on the prevalence and prognostic impact of IGT in patients with congestive HF. We recommend that 75-g OGTT should be performed in all patients with HF to allow for precise risk stratification.

The present study had some limitations. First, this study was based on a small number of patients at a single center. The cohort in the present study included only patients with HF who required hospitalization, and thus the data described herein cannot be extrapolated to the whole HF population. We did not evaluate diastolic function on echocardiography because the subjects included a considerable number of patients with atrial fibrillation. Finally, the presence or absence of glucose intolerance was determined by the attending physician who also decided whether admission for treatment was required, and this may have affected the rate of readmission in the present study.

\section{Conclusions}

In patients with HF, IGT is a common comorbidity, and IGT contributes to poor prognosis in a similar fashion to DM as an independent factor. These findings suggest the importance of using OGTT to detect glucose intolerance and identify highrisk patients in this population.

\section{References}

1. Nakatani D, Sakata Y, Mizuno H, Shimizu M, Suna S, Usami M, et al; Osaka Acute Coronary Insufficiency Study (OACIS) Group. Impact of diabetes mellitus on rehospitalization for heart failure among survivors of acute myocardial infarction in the percutaneous coronary intervention era. Circ J 2009; 73: 662-666.

2. Kannel WB, Hjortland M, Castelli WP. Role of diabetes in congestive heart failure: The Framingham study. Am J Cardiol 1974; 34: $29-34$.

3. Havranek EP, Masoudi FA, Westfall KA, Wolfe P, Ordin DL, Krumholz HM. Spectrum of heart failure in older patients: Results from the National Heart Failure project. Am Heart J 2002; 143: 412 417.

4. MacDonald MR, Petrie MC, Varyani F, Ostergren J, Michelson EL, Young JB, et al. Impact of diabetes on outcomes in patients with low and preserved ejection fraction heart failure: An analysis of the Candesartan in Heart failure: Assessment of Reduction in Mortality and morbidity (CHARM) programme. Eur Heart J 2008; 29: 1377 1385.

5. Domanski M, Krause-Steinrauf H, Deedwania P, Follmann D, Ghali JK, Gilbert E, et al. The effect of diabetes on outcomes of patients with advanced heart failure in the BEST trial. $J$ Am Coll Cardiol 2003; 42: 914-922.

6. Miura Y, Fukumoto Y, Shiba N, Miura T, Shimada K, Iwama Y, et al. Prevalence and clinical implication of metabolic syndrome in chronic heart failure. Circ J 2010; 74: 2612-2621.

7. Goode KM, John J, Rigby AS, Kilpatrick ES, Atkin SL, Bragadeesh $\mathrm{T}$, et al. Elevated glycated haemoglobin is a strong predictor of mortality in patients with left ventricular systolic dysfunction who are not receiving treatment for diabetes mellitus. Heart 2009; 95: 917-923.

8. Berry C, Brett M, Stevenson K, McMurray JJ, Norrie J. Nature and prognostic importance of abnormal glucose tolerance and diabetes in acute heart failure. Heart 2008; 94: 296-304.

9. Gerstein HC, Swedberg K, Carlsson J, McMurray JJ, Michelson EL, Olofsson B, et al. The hemoglobin Alc level as a progressive risk factor for cardiovascular death, hospitalization for heart failure, or death in patients with chronic heart failure: An analysis of the Can- desartan in Heart failure: Assessment of Reduction in Mortality and Morbidity (CHARM) program. Arch Intern Med 2008; 168: 16991704.

10. Kosiborod M, Inzucchi SE, Spertus JA, Wang Y, Masoudi FA, Havranek EP, et al. Elevated admission glucose and mortality in elderly patients hospitalized with heart failure. Circulation 2009; 119: $1899-1907$.

11. Ho KK, Anderson KM, Kannel WB, Grossman W, Levy D. Survival after the onset of congestive heart failure in Framingham Heart Study subjects. Circulation 1993; 88: 107-115.

12. World Health Organization. Definition, diagnosis and classification of diabetes mellitus and its complications: Report of a WHO Consultation. Part 1: Diagnosis and classification of diabetes mellitus. Geneva, World Health Organization, 1999.

13. Matsuo S, Imai E, Horio M, Yasuda Y, Tomita K, Nitta K, et al. Revised equations for estimated GFR from serum creatinine in Japan. Am J Kidney Dis 2009; 53: 982-992.

14. Witteles RM, Tang WH, Jamali AH, Chu JW, Reaven GM, Fowler MB. Insulin resistance in idiopathic dilated cardiomyopathy: A possible etiologic link. J Am Coll Cardiol 2004; 44: 78-81.

15. Swan JW, Anker SD, Walton C, Godsland IF, Clark AL, Leyva F, et al. Insulin resistance in chronic heart failure: Relation to severity and etiology of heart failure. J Am Coll Cardiol 1997; 30: 527-532.

16. Suskin N, McKelvie RS, Burns RJ, Latini R, Pericak D, Probstfield $\mathrm{J}$, et al. Glucose and insulin abnormalities relate to functional capacity in patients with congestive heart failure. Eur Heart J 2000; 21: $1368-1375$.

17. Egstrup M, Schou M, Gustafsson I, Kistorp CN, Hildebrandt PR, Tuxen CD. Oral glucose tolerance testing in an outpatient heart failure clinic reveals a high proportion of undiagnosed diabetic patients with an adverse prognosis. Eur J Heart Fail 2011; 13: 319-326.

18. Ishihara M, Inoue I, Kawagoe T, Shimatani Y, Kurisu S, Hata T, et al. Is admission hyperglycaemia in non-diabetic patients with acute myocardial infarction a surrogate for previously undiagnosed abnormal glucose tolerance? Eur Heart J 2006; 27: 2413-2419.

19. Thrainsdottir IS, Aspelund T, Hardarson T, Malmberg K, Sigurdsson G, Thorgeirsson G, et al. Glucose abnormalities and heart failure predict poor prognosis in the population-based Reykjavik Study. Eur J Cardiovasc Prev Rehabil 2005; 12: 465-471.

20. Rydén L, Standl E, Bartnik M, Van den Berghe G, Betteridge J, de Boer MJ, et al; Task Force on Diabetes and Cardiovascular Diseases of the European Society of Cardiology (ESC); European Association for the Study of Diabetes (EASD). Guidelines on diabetes, pre-diabetes, and cardiovascular diseases: Executive summary. The Task Force on Diabetes and Cardiovascular Diseases of the European Society of Cardiology (ESC) and of the European Association for the Study of Diabetes (EASD). Eur Heart J 2007; 28: 88-136.

21. DECODE Study Group, the European Diabetes Epidemiology Group. Glucose tolerance and cardiovascular mortality: Comparison of fasting and 2-hour diagnostic criteria. Arch Intern Med 2001; 161: $397-405$.

22. Coutinho M, Gerstein HC, Wang Y, Yusuf S. The relationship between glucose and incident cardiovascular events: A metaregression analysis of published data from 20 studies of 95,783 individuals followed for 12.4 years. Diabetes Care 1999; 22: 233-240.

23. Shimabukuro M, Higa N, Asahi T, Yamakawa K, Oshiro Y, Higa M, et al. Impaired glucose tolerance, but not impaired fasting glucose, underlies left ventricular diastolic dysfunction. Diabetes Care 2011; 34: $686-690$.

24. Kim J, Nakatani S, Hashimura K, Komamura K, Kanzaki H, Asakura $\mathrm{M}$, et al. Abnormal glucose tolerance contributes to the progression of chronic heart failure in patients with dilated cardiomyopathy. Hypertens Res 2006; 29: 775-782.

25. Chiasson JL, Josse RG, Gomis R, Hanefeld M, Karasik A, Laakso M; STOP-NIDDM Trial Research Group. Acarbose treatment and the risk of cardiovascular disease and hypertension in patients with impaired glucose tolerance: The STOP-NIDDM trial. JAMA 2003; 290: $486-494$.

26. Ceriello A. The post-prandial state and cardiovascular disease: Relevance to diabetes mellitus. Diabetes Metab Res Rev 2000; 16: 125 132.

27. De Vriese AS, Verbeuren TJ, Van de Voorde J, Lameire NH, Vanhoutte PM. Endothelial dysfunction in diabetes. Br J Pharmacol 2000; 130: 963-974.

28. Temelkova-Kurktschiev T, Henkel E, Koehler C, Karrei K, Hanefeld M. Subclinical inflammation in newly detected type II diabetes and impaired glucose tolerance. Diabetologia 2002; 45: 151.

29. Node K, Inoue T. Postprandial hyperglycemia as an etiological factor in vascular failure. Cardiovasc Diabetol 2009; 8: 23. 